\title{
Linking acoustic velocity of standing Douglas-fir trees to veneer stiffness: a tree-log-product study across thinning treatments
}

\author{
Eini C Lowell ${ }^{1 * \dagger}$, Christine L Todoroki ${ }^{2 \dagger}$, Dennis P Dykstra ${ }^{3}$ and David G Briggs ${ }^{4}$
}

\begin{abstract}
Background: To understand the effects of silvicultural treatments on tree and product modulus of elasticity (MOE), an intensive study along the stand-tree-product value chain was conducted. Acoustic tests were performed on 460 Douglas-fir (Pseudotsuga menziesii (Mirb.) Franco) trees from two sites in the US Pacific Northwest.

Methods: Trees on a site in Washington were 51 years old, while those situated in Oregon were 45 years old. Both sites comprised five plots: Plot A was the control, while Plots B, C, D, and E were prescribed with differing thinning treatments. Acoustic readings were stratified, and a sample of six trees per plot randomly selected from the stratified samples. Trees were harvested, cross-cut, and peeled into veneer. Veneer was acoustically tested, and density and MOE calculated for each sheet. Veneer sheets were grouped by parent bolt and tree, and MOE of the butt veneer bolt and the parent tree determined from the mean. Plot means were compared using one-way analysis of variance (ANOVA), and regression models developed with mean tree MOE as the response variable and non-destructive tree measures as explanatory variables. Further models were developed to demonstrate the relationship between tree diameter and the number of veneer sheets peeled, and between MOE of the parent tree and butt bolt.
\end{abstract}

Results: MOE was negatively correlated with diameter and taper, and positively correlated with acoustic velocity, $\mathrm{V}$. The relationship with $V^{2}$, following the wave equation $\left(\mathrm{MOE}=\rho V^{2}\right)$ under the assumption of constant density, $\rho$, was no better than that with $V$. While the correlations suggest that thinning regimes that cause rapid diameter growth and increased taper may be susceptible to a reduction in overall stiffness, there was no evidence, as determined by ANOVA, to suggest that thinning reduces stiffness. On the contrary, mean MOE at plot E (light thinning) was 12.6 GPa and the control was 10.2 GPa, with the difference significant at the $10 \%$ level ( $p$-value $=0.074$ ).

Conclusions: In general, trees with MOE exceeding the recommended tree breeding value of $11 \mathrm{GPa}$ were of low taper and small diameter, suggesting that regimes with a lesser impact on taper and diameter, as demonstrated by Plot $E$, are worthy of further investigation.

Keywords: Modulus of elasticity; Wood density; Stand density; Tree breeding; Veneer; Acoustic velocity; Douglas-fir

\section{Background}

Evaluation and estimation of the properties of products that can be expected from standing trees is important to tree breeders, growers and wood processors alike. For Douglas-fir (Pseudotsuga menziesii (Mirb.) Franco), stiffness has been identified as one of the most important properties, particularly for engineered products such as

\footnotetext{
* Correspondence: elowell@fs.fed.us

${ }^{\dagger}$ Equal contributors

'US Forest Service, Portland Forestry Sciences Laboratory, 620 SW Main, Suite 400, Portland, OR 97205, USA

Full list of author information is available at the end of the article
}

plywood and laminated veneers. Until recently, such high-stiffness products were typically derived from old growth Douglas-fir but with the shift of raw material base from old growth to second growth and fast-grown plantation wood there are concerns for future wood quality (Kennedy 1995). To address these concerns there is increasing interest in including wood stiffness, a highly heritable wood property, in Douglas-fir tree breeding programmes (Johnson and Gartner 2006, Shelbourne et al. 2007, Vikram et al. 2011). To this end, a preliminary breeding objective (which landowners may choose to 
exceed) of 1.6 million psi average whole-tree stiffness has been proposed (Jayawickrama et al. 2009). The proposed breeding objective corresponds to $11 \mathrm{GPa}$.

Provision of a target stiffness breeding objective is useful for screening, selection, and breeding in tree improvement programmes. Lindström et al. (2002) emphasised that stiffness needs to be evaluated, and used for selection, all along the value chain - from seed through final wood product. If elite populations of high-stiffness seedlots were subsequently grown and silvicultural treatments applied for a designated end use, the purpose-bred and purposegrown trees could potentially realise even greater benefits upon harvest.

Acoustic tools have become widely adopted by industry to assess the potential stiffness of standing trees at, or prior to, harvest. These tools measure the time it takes for an acoustic wave to travel a known distance along the stem. One type of acoustic tool is based on resonance but it cannot be used on standing trees because it requires two cut surfaces for the wave to resonate between. Another type of acoustic tool is based on time-of-flight, and is the only type of tool that can be used on standing trees. Resonance tools are more accurate but time-of-flight tools have the benefit of being non-destructive on standing trees. Consequently, a body of research has focussed on linking the two types of tools (e.g. Raymond et al. 2008, Wang 2013). The resonance-based tools have been applied in numerous research studies, with research samples such as small clear specimens (e.g. Wang et al. 2001, Auty and Achim 2008) that, for practical reasons, are obtained from limited sampling points within the tree, and sometimes only at one point (e.g. breast height). However, as mentioned by Wessels et al. (2011), knowledge of the relationship between properties at the points measured in a tree and the variation throughout the tree and the stand, is required to make whole-tree and stand-based property predictions.

It should be noted that acoustic tools are not without limitations. One of the principal limitations of time-offlight tools is that they measure outerwood stiffness, rather than stiffness across and throughout the entire stem (Chauhan and Walker 2006, Lasserre et al. 2007, Mora et al. 2009). Another limitation is that they rely on the assumption of constant density. This follows from the fundamental wave Equation (1) that states that the stiffness, or modulus of elasticity (MOE), of a homogeneous and isotropic material (of which wood is neither (Zobel and van Buijtenen 1989)) is equal to the square of the acoustic velocity multiplied by its density.

$$
M O E=\rho v^{2}
$$

A green density for wood of $1000 \mathrm{~kg} \mathrm{~m}^{-3}$ irrespective of species and age has commonly been assumed by researchers (e.g. Pellerin and Ross 2002). For example, Lasserre et al. (2004) applied a constant density of $1000 \mathrm{~kg} \mathrm{~m}^{-3}$ to their study of 11 year-old radiata pine (Pinus radiata D.Don) trees. The value was subsequently adopted by Raymond et al. (2008) in their study of 28 to 43-year-old radiata pine trees from both thinned and un-thinned stands, and by Moore et al. (2009) for Sitka spruce (Picea sitchensis (Bong.) Carr.) aged 35 to 50 years. The assumption that wood density is always the same as that of 11-year-old radiata pine trees, and is unchanged by thinning, pruning, site, species, or age has not been conclusively established. However Wielinga et al. (2009) did test the validity of the assumption and found that the density of the outer five rings was relatively constant, therefore making $\mathrm{V}^{2}$ an appropriate measure of tree stiffness in the outerwood for 13-yearold radiata pine trees. In contrast, non-constant values that demonstrated a stand-age effect, were reported for three stands of radiata pine growing in close proximity to one another. Mean outerwood green density of stands aged 8,16 , and 25 years was 1110,1123 , and $1131 \mathrm{~kg} \mathrm{~m}^{-3}$ respectively (Chauhan and Walker 2006).

As wood is a heterogeneous and anisotropic material, its density is a complex property that is difficult to assess in situ. However, some progress towards in situ density measurements has been made. A fine drill that penetrates standing trees from bark to bark has been used to obtain data on green-wood density and to demonstrate its variation within a tree (Isik and Li 2003, El-Kassaby et al. 2011). In the absence of such samples, density is usually assessed under laboratory conditions using volumetric or X-ray densitometry methods. Such methods entail extraction of increment cores and measurement of the volume and mass of oven-dried samples. Under laboratory conditions, evidence of non-constant basic density has also been clearly demonstrated (e.g. Kang et al. 2011, Bender et al. 2012) together with evidence demonstrating increased outerwood density with increasing age (Blakemore et al. 2010).

Waddell et al. (1987) found that the relationship between basic density and relative height followed a cubic trend within old-growth Douglas-fir trees; with a large degree of variation about the trend. Variation in basic density, which can be related to both growth rate and age (Jozsa et al. 1989; Cave and Walker 1994), is exhibited by a radial gradient in many softwood species (Sanio 1872; Trendelenburg 1936) with several reports of similar trends for Douglas-fir (Wellwood and Smith 1962; Kennedy and Warren 1969; Megraw 1986; Jozsa et al. 1989). More recent studies of second-growth Douglas-fir have demonstrated changing density (Gartner et al. 2002) and stiffness (Langum et al. 2009) in radial and vertical directions within trees, and noticeable differences in both wood properties among trees (Todoroki et al. 2012). 
In the latter study, the relationship between density and radius followed a quadratic trend in the pith to bark direction (with radius measured from a zone of approximately $4.5 \mathrm{~cm}$ beyond the pith), and a similar trend was found for stiffness. The relationships, which were incorporated in models to estimate wood properties within individual trees, did not explicitly account for the effects of silvicultural treatments.

Time-of-flight tools have become very popular in spite of their limitations. One reason for this popularity is that they allow in situ non-destructive measurements to be obtained. If the rank order of the measurements is reliable, then trees can be successfully segregated into appropriate processing pathways. Huang (2000) demonstrated that tree acoustic velocity alone was useful in identifying the upper $15 \%$ of loblolly pine (Pinus taeda L.) trees with the potential to produce stiff timber. The lower 15\% could also be identified by acoustic velocity alone. In contrast, Amishev and Murphy (2008) did not find a significant correlation between standing tree acoustic velocity and the proportion of veneer exceeding a predefined stiffness threshold, and concluded that acoustic velocity alone was not reliable.

Acoustic velocity in standing trees has been found to change with tree age, diameter, and stand silviculture. In a study of 966 Douglas-fir trees of two age classes (33 to 35 and 48 to 50 years), Briggs et al. (2008) found acoustic velocity increased with increasing age and decreased with increasing diameter. For 20-year-old Taiwania (Taiwania cryptomerioides Hayata) trees, Wang et al. (2000) found that heavy thinning (defined as a reduction of stand density from 1750 to 929 stems per hectare) significantly reduced acoustic velocity, though moderate thinning (from 1689 to 1135 stems per hectare) did not.

Thinning operations generally cause increased diameter growth (Reukema 1975; Tappeiner et al. 1982). Thinning can also cause an increase in height under some circumstances but site quality can also affect height. Height of Douglas-fir increased with increasing thinning intensity on sites with a low site index of $37 \mathrm{~m}$ (McArdle et al. 1961; Curtis and Reukema 1970) but height growth rates were similar across thinning treatments on sites with higher indices of 49-52 m (Tappeiner et al. 1982).

Increased thinning intensity has been found to increase taper in trees and hence reduce yields. Weiskittel et al. (2006) found a reduction of almost $5 \%$ in volume due to increased taper in trees from thinned stands of Douglas-fir in contrast to trees of similar diameter and height in un-thinned stands. Shelbourne et al. (1973) similarly found individual-tree volume to be negatively correlated with stiffness in a study of New Zealandgrown Douglas-fir trees growing on one site. These authors also noted that trees that produced high stiffness timber tended to have small branches, small stem diameters, straight stems, and high wood density. Therefore a reduction in individual tree-volume is not necessarily detrimental to stiffness, but may be the main cost that would need to be borne by tree improvement programmes that include stiffness (Jayawickrama et al. 2009).

The aim of this study was to address many of the concerns raised above, including assessing stiffness and density, at all possible points within trees. The following issues are also addressed:

1) What are the relationships between average stiffness of products derived from the butt log and that of the parent tree, and to what extent are these relationships influenced by easily measurable, non-destructive tree variables?

2) What are the effects of silvicultural treatments on these stiffness relationships?

3) How can the natural variability of stiffness among trees within a stand be monitored and incorporated into decision support tools that assist managers in assessments and in making improved marketing decisions?

In this tree-log-product study across differing silvicultural treatments, the product under examination is veneer. All possible veneer sheets that could be peeled from each tree were assessed for density and stiffness. The veneer stiffness data was then collated at the tree level to calculate mean tree stiffness. Information relating to the alternative processing pathway, from tree to timber, is reported by Briggs et al. (2008).

\section{Methods}

This study was performed across two sites, each comprising five plots that represented differing thinning treatments. All trees on each plot, within a specified area, were acoustically assessed. The acoustic data for each plot was pooled then acoustic velocity distributions developed and stratified. From within each stratum, trees were randomly selected for processing into veneer. Further details of the stratification process for sample veneer tree selection, and details of the sites, plots and treatments, and veneer processing methodology follow.

\section{Study sites}

The two sites were selected from permanent installations of a long-term research trial investigating the effects of silvicultural treatments on growth, yield, and wood quality. The plots were located in the US Pacific Northwest region, one in Washington $\left(47^{\circ} 16^{\prime} \mathrm{N}, 123^{\circ} 27^{\prime} \mathrm{W}\right.$, elevation $175 \mathrm{~m})$, the other in Oregon $\left(44^{\circ} 57^{\prime} \mathrm{N}, 123^{\circ} 40^{\prime} \mathrm{W}\right.$, elevation $765 \mathrm{~m}$ ). The Washington site, Site 803, had a site index of $44 \mathrm{~m}$ (following the definition of King (1966)) while the Oregon site, Site 808, had a site index 
of $40 \mathrm{~m}$. The plots at each site were established on commercial forest land in existing plantations that had been re-spaced more than 10 years prior to plot establishment. Trees were approaching commercial thinning stage at time of establishment. The requisite relative density (basal area divided by the square root of quadratic mean diameter, Curtis 1982) for the plots was 55, or less at establishment. This situation necessitated a quadratic mean diameter of $15-25 \mathrm{~cm}$ for an initial target stocking rate within a range of 500-1112 stems per hectare. Full details of plot establishment and experimental design are provided in Maguire et al. (1991). The plots were subsequently monitored by the Stand Management Cooperative, a consortium of landowners and research institutions in the Pacific Northwest formed in 1985.

\section{Plots and treatments}

Both sites contained five plots, each measuring 0.47 hectares, within a thinning trial. Each plot within the trial contained a square 0.20 ha measurement sample plot surrounded by a treatment buffer. The control plot, Plot A, was un-thinned, while the remainder were treated according to prescribed thinning regimes based on relative density (RD). As an example, the regime for Plot B, designated RD55-RD30, specifies that when the relative density of the stand attains the value of 55 (the thinning trigger), the stand should be thinned to a relative density of 30 . Thinning prescriptions, summarised for each plot in Table 1, assume basal area to be measured in square feet and quadratic mean diameter in inches. A factor of 0.144 can be used to convert units of RD to $\mathrm{m}^{2} \mathrm{ha}^{-1} \mathrm{~cm}^{-1 / 2}$, assuming basal area to be measured in square metres and quadratic mean diameter in centimetres. Though thinning was prescribed for Plot $\mathrm{C}$ at Site 803, the trigger was not attained and thus no thinning occurred. The prescription for Plots D and E at Site 803 called for repeated thinning but only the first trigger point was reached so only the one thinning occurred. Plots B, D, and E at Site 803 were all thinned in 1987 when the trees were aged approximately 33 years. Site
803 trees were harvested in 2006 when the trees were approximately 51 years of age. Plots B and E at Site 808 were thinned in 1991, when aged 31 years, and plots C and D in 1993 when aged 33 years. At Site 808, and subsequent to thinning, Plot $\mathrm{C}$ was lost from the trial due to storm damage before any further measurements could be taken. At harvest, trees at Site 808 were approximately 45 years of age. Tree ages within the plots were estimated from ring counts at the base of the butt logs.

At harvest, Curtis' relative density on site 803 plots A through $E$ was $61,49,58,51$, and 54 respectively and, on site $808,71,46,42,53$ for plots A, B, D, and E respectively. Stocking levels at harvest ranged from 242 to 558 stems per hectare, and at establishment from 469 to 899 stems per hectare. The change in relative density of each plot, from the time of establishment, after thinning, and with subsequent growth, is shown in the upper two graphs of Figure 1 (darker colours are representative of greater thinning intensities) for Sites 803 and 808 respectively. The associated stand densities are shown in the lower two graphs of the figure. While no thinning occurred on Plot A (nor Plot C, Site 803), a large degree of mortality occurred, primarily as a result of wind damage from a 1995 storm, and is apparent in the figure.

\section{Experimental design for tree selection}

Stratified random sampling was used to select trees within plots, and the strata formed on the basis of timeof-flight acoustic tree measurements. All trees within a circular 0.1 ha plot established at the centre of each measurement plot were acoustically assessed. This amounted to a total of 460 trees, i.e. about 50 trees per plot. Nine readings (three at each of three locations approximately 120 degrees apart) were obtained for each tree, over a one-metre distance centred at breast height (following Briggs et al. 2008), using the TreeSonic ${ }^{\mathrm{Tm}}$ timer (Fakopp Bt. Agfalva, Hungary). Acoustic time-of-flight readings were averaged, listed in ascending order, and classified on a plot-by-plot basis. The classification system divided the trees on each plot into one of four classes according to acoustic time-of-flight readings: $1=0-10 \%$ of

Table 1 Thinning treatments, prescribed and actual, for the Douglas-fir trees growing on the two sites

\begin{tabular}{llll}
\hline & \multicolumn{1}{c}{ Thinning Prescription } & \multicolumn{2}{c}{ Actual Treatment } \\
\cline { 3 - 4 } Plot & Relative density thinning triggers ${ }^{1}$ & Site $\mathbf{8 0 3}$ & Site $\mathbf{8 0 8}$ \\
\hline A & Control & Control & Control \\
B & RD55-RD30 & RD55-RD30 attained; one thinning. & RD55-RD30 attained; one thinning. \\
C & RD65-RD35 & RD65 not attained; no thinning. & RD65 attained; one thinning. ${ }^{2}$ \\
D & RD55-RD30 then RD50-RD30 & RD55 attained; one thinning. RD50 & RD55 attained; one thinning. RD50 \\
& & not attained; no further thinning. & not attained; no further thinning. \\
E & RD55-RD35 then RD55-RD40 then RD60-RD40 & First RD55 attained; one thinning. Second & First RD55 attained; one thinning. Second \\
& & RD55 not attained; no further thinning. & RD55 not attained; no further thinning. \\
\hline
\end{tabular}

\footnotetext{
${ }^{1}$ Thinning triggers are defined by stand relative density (RD), thus when the stand reaches a RD of $x$, thin to leave the stand with a RD of $y$ (RDx-RDy).
}

2 Plot later lost due to storm. 

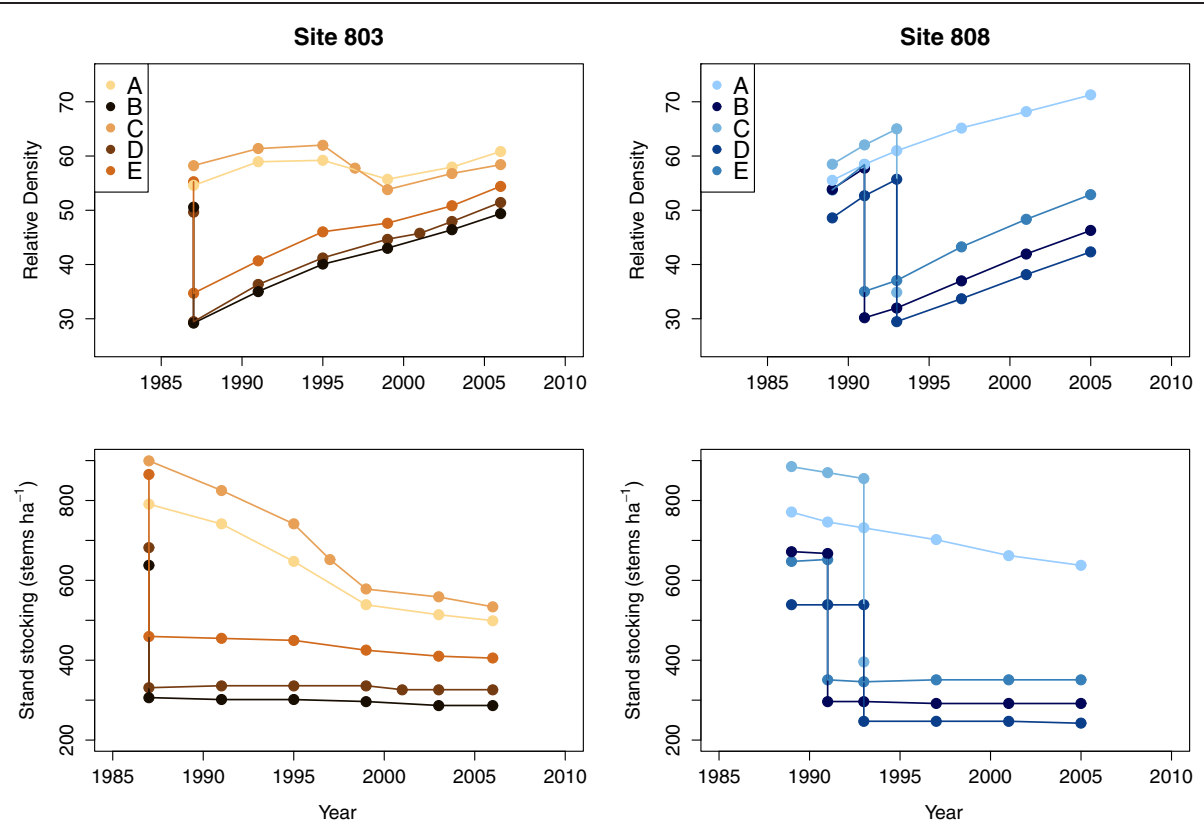

Figure 1 Relative density (top) and stand stocking density (bottom) from the time of establishment to harvest for Douglas-fir thinning treatments A through E at Sites $\mathbf{8 0 3}$ (left) and $\mathbf{8 0 8}$ (right). Vertical lines connect density before and after thinning. Darker colours represent increased thinning intensity.

acoustic readings, $2=11-40 \%, 3=41-90 \%, 4=91-100 \%$. Note that time class 1 is equivalent to high velocity, and time class 4 is equivalent to low velocity, due to the inverse relationship between time and velocity.

One tree of Class 1, two each of Classes 2 (2a and 2b) and 3 ( $3 \mathrm{a}$ and $3 \mathrm{~b}$ ), and one of Class 4 , were randomly selected from each plot for conversion to veneer, resulting in six trees per plot, and a total of 30 trees at Site 803 and 24 at Site 808 . If a sample tree was found to have defects (such as forks, crooks, pistol butt, rot) during the selection process that would compromise the main objective of the study, then a replacement tree was randomly selected. This reselection process was performed because examination of the effect of various types of defects on acoustic velocity or recovery relationships was beyond the scope of the present study. The design approach is illustrated in Figure 2. For each plot, acoustic velocity distributions of all trees tested within the predefined area (solid curved line), the strata boundaries (dotted vertical lines), and the sample trees randomly selected within each strata for processing into veneer (represented by filled circles) are shown.

In addition to the velocity readings, further measurements were made on the sample trees. Diameter at breast height, $1.4 \mathrm{~m}$, (D) was measured prior to harvest. After felling, stump diameter, stump height, and total tree height $(\mathrm{H})$ were recorded. Tree height was estimated in one case (the Class 4 tree from Plot A, Site 803) because the top of the tree broke during felling and it was not found. The ratio of diameter at the stump to the vertical height of the tree measured from stump to apex was used to calculate tree taper (T).

Felled trees were crosscut into $10.67 \mathrm{~m}$ long logs, from which two $5.33 \mathrm{~m}$ mill-length logs were obtained. Each mill-length log was crosscut into two veneer bolts (peeler blocks) which were steamed and peeled into veneer until the core measured approximately $8.9 \mathrm{~cm}$ in diameter. The veneer sheets were tracked during the peeling process, allowing each sheet to be uniquely traced back to the veneer bolt and consequently to the position within the bolt, log, and parent tree, thus enabling the construction of internal stiffness maps for each tree (after Todoroki et al. 2012).

\section{Veneer density}

Within-tree density variation was captured from the individual veneer sheets. Full veneer sheets (with dry target sizes of $2.59 \mathrm{~m}$ in length, $1.32 \mathrm{~m}$ in width, and $3.8 \mathrm{~mm}$ in thickness) and half-sheets ( $0.66 \mathrm{~m}$ wide) were individually weighed and measured after drying (sheets equilibrated to approximately $10 \%$ moisture content), and density calculated for each sheet from the sheet mass divided by the product of length $\mathrm{x}$ width $\mathrm{x}$ thickness. Individual sheet densities were used in calculations of the mean density of each parent tree.

\section{Veneer stiffness}

Veneer was non-destructively tested using a Metriguard $2600^{\text {тм }}$ veneer tester (Metriguard Inc., Pullman, WA, USA). Up to four tests were conducted per sheet with 


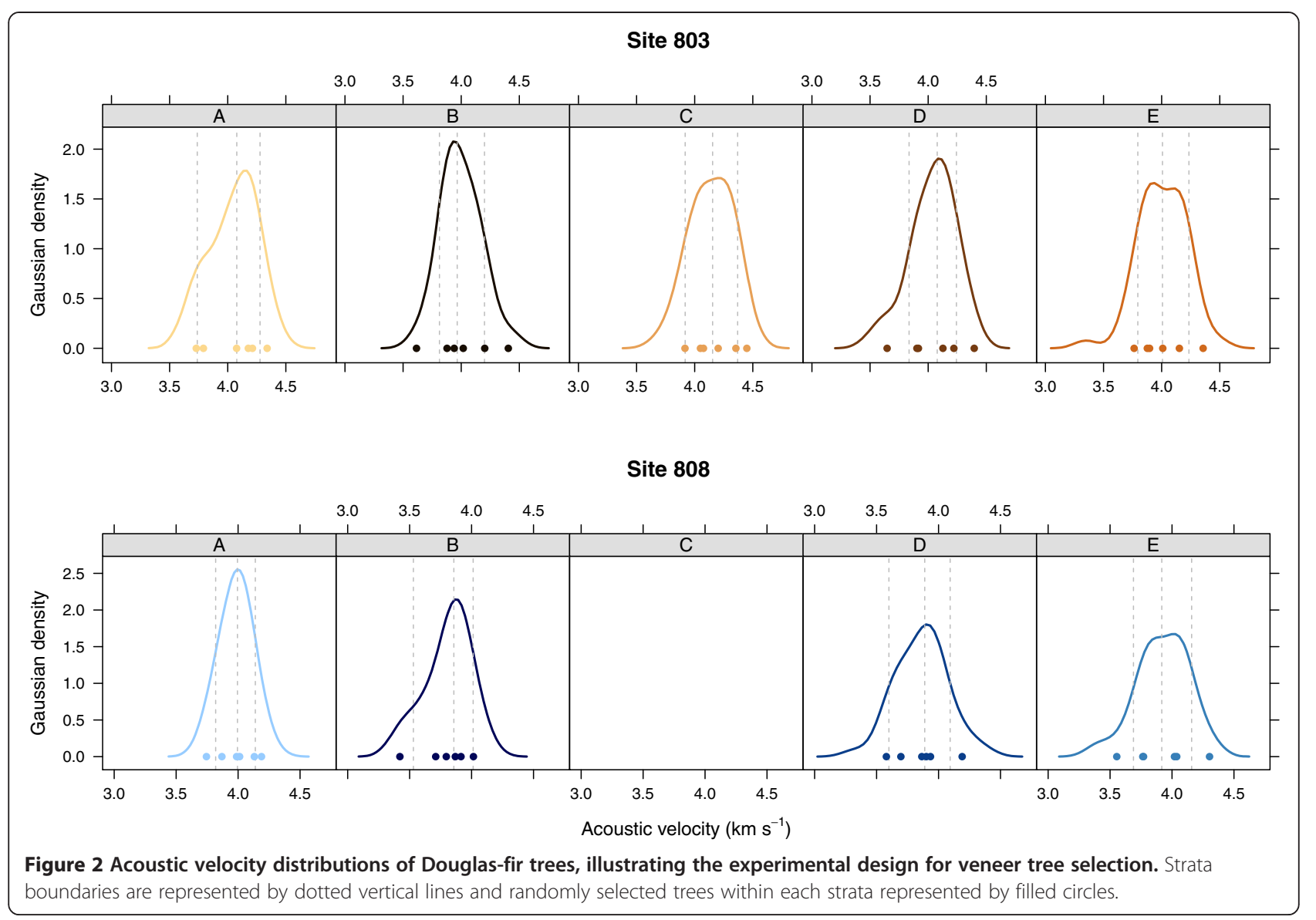

readings taken close to both ends of the veneer sheet and at one-third and two-thirds the length of the sheet. Stiffness of veneer sheets $\left(\mathrm{MOE}_{\mathrm{V}}\right)$ was calculated from sheet mass $(\mathrm{m})$, sheet width $(\mathrm{w})$, length $(\mathrm{l})$, thickness $(\mathrm{t})$, and veneer acoustic velocity, $v$, determined from the inverse of the mean transit time reading (Equation 2).

$$
M O E_{V}=\frac{m}{l \cdot w \cdot t} v^{2}
$$

On a few occasions, where a single sheet from among those peeled from a veneer bolt was either missing or the acoustic reading unavailable because of features (such as knot whorls, grain disturbance, or natural fracture lines), stiffness was estimated using regression analysis. A quadratic model was chosen following Todoroki et al. (2012) and from observation of the typical curvilinear relationship between veneer stiffness and distance from core (Figure 3). The explanatory variable was veneer sheet as indexed from the core, and the response variable was veneer stiffness. Estimation, rather than omission, of unobserved stiffness values was used to reduce bias, caused by the spatial nature of the data, in the calculation of mean-tree veneer stiffness. For example, if stiffness values were missing from sheets near the core and omitted from calculations, then mean tree veneer stiffness would be over-estimated. On the other hand, if observations were missing from near the bark, mean tree veneer stiffness would be under-estimated. An example of estimating the value for a missing veneer sheet is shown in Figure 3 (filled in circle).

Due to several unforeseen circumstances, problems were encountered with some veneer bolts, particularly those from Site 808. A regression approach was initially considered for estimating missing values but use of predictive equations for extrapolation of data, rather than interpolation, could provide unreliable estimates of stiffness. Thus, the decision was made to concentrate on veneer from the first veneer bolt of the butt $\log$ of each tree from Site 808 for which veneer data remained reasonably intact. For one tree from Site 808 (A1), and also one tree from Site $803(\mathrm{C} 1)$, data from the first veneer bolt from the butt log were missing, so data from the second veneer bolt were substituted. It was therefore expected that the mean stiffness of these two bolts, and the mean stiffness of tree $\mathrm{C} 1$ at Site 803 , would be slightly under-estimated. 


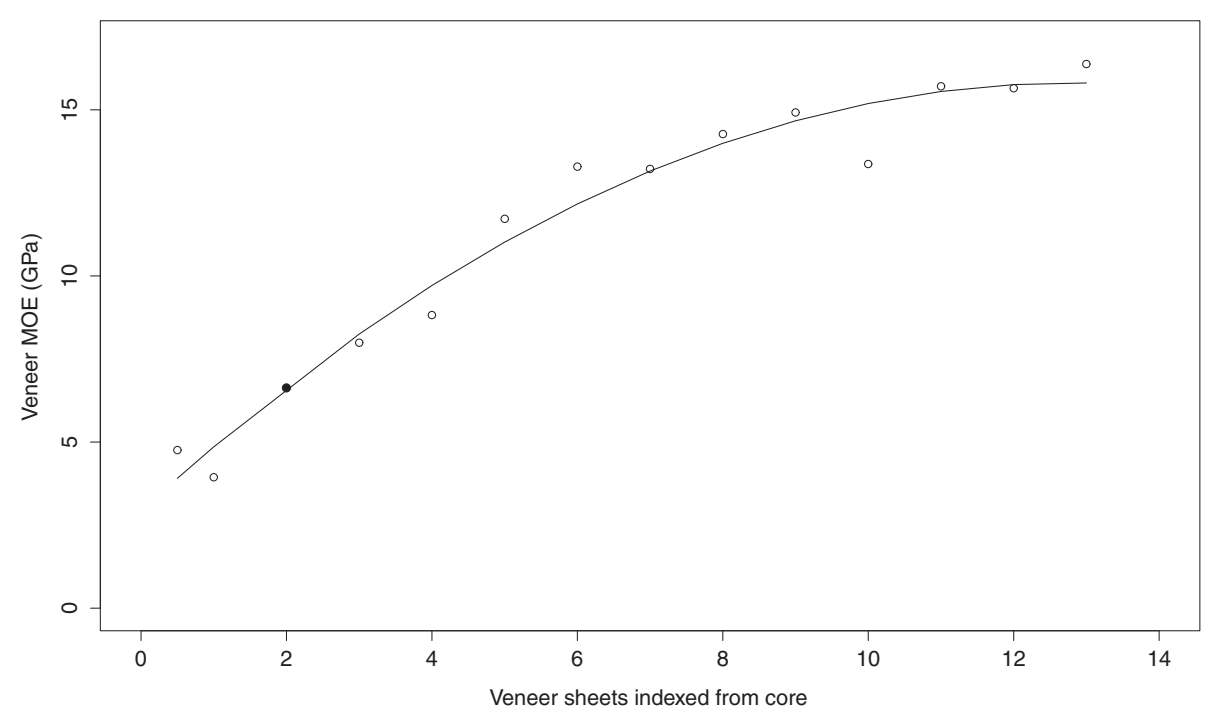

Figure 3 Example of the typical curvilinear relationship between veneer stiffness and distance from core, and stiffness estimation for a missing sheet (represented by a filled circle) within a veneer bolt.

\section{Average tree and bolt stiffness}

Mean stiffness of veneer peeled from each tree $\left(\mathrm{MOE}_{\mathrm{T}}\right)$ was calculated only for trees from Site 803, with halfsheets weighted at half the value of full sheets, as:

$$
M O E_{T}=\frac{\sum_{i=1}^{N_{T}} w_{i} \rho_{i} v_{i}^{2}}{\sum_{i=1}^{N_{T}} w_{i}}
$$

where $\mathrm{N}_{T}$ is the total number of veneer sheets peeled from each tree, and for each veneer sheet $i, \mathrm{w}_{i}$ is the weighting, equal to 1 for full sheets, 0.5 for half-sheets, $\rho_{\mathrm{i}}$ is the density of the veneer sheet (calculated as shown in Equation 2), and $v_{i}$ the acoustic velocity of the sheet.

At the veneer bolt level, mean stiffness of veneer within the lowermost bolt $\left(\mathrm{MOE}_{\mathrm{L}}\right)$ was calculated, with half-sheets weighted at half the value of full sheets, as

$$
M O E_{L}=\frac{\sum_{i=1}^{N_{L}} w_{i} \rho_{i} v_{i}^{2}}{\sum_{i=1}^{N_{L}} w_{i}}
$$

where $\mathrm{N}_{L}$ is the number of veneer sheets peeled from the bolt, and all other variables are as described above.

\section{Data analyses}

Data were analysed using the $\mathrm{R}$ statistical software package (R Development Core Team 2013). Both graphical and statistical approaches were employed in order to observe differences in stiffness within trees and among trees, and across acoustic classes and thinning treatments. The veneer stiffness data, $\mathrm{MOE}_{\mathrm{V}}$, were grouped by parent tree, then the range, inter-quartile range and median stiffness within each tree compared using box plots. This graphical approach provided a useful visual check for normality, skewness, homogeneity of variance, and detection of outliers (Quinn and Keough 2002) within trees. Mean tree stiffness, $\mathrm{MOE}_{\mathrm{T}}$, was super-imposed on each box plot and comparisons made using analysis of variance (ANOVA). A one-way ANOVA was conducted to determine if differences between the thinning treatments were significant. For post-hoc testing, the Tukey Honestly Significant Difference (HSD) was chosen for conducting pairwise comparisons.

The student's t-test was used to test for differences in acoustic tree sample variables between the two sites. To reduce potential sources of bias due to the additional 52 un-thinned trees on plot C Site 803 (since plot C on Site 808 was dropped due to extensive storm damage), the $\mathrm{t}$ tests were conducted without that dataset. A significance level of 0.05 was applied.

To investigate the relationship between stiffness of parent trees and tree variables, data were plotted and simple linear regression models developed using $\mathrm{MOE}_{\mathrm{T}}$ as the response variable and $\mathrm{V}, \mathrm{D}, \mathrm{H}$, and $\mathrm{T}$ as explanatory variables. $\mathrm{V}^{2}$ was also tested as an explanatory variable (following Equation 1). Note that the strength of the relationship between $\mathrm{MOE}_{\mathrm{T}}$ and $\mathrm{V}^{2}$ remains unaltered by any multiplicative constant that would represent constant wood density. However, the relationship will be weakened if the intercept is set equal to zero, as is the case in Equation 1. Both model forms, with and without the intercept, were evaluated. Linear regression models with $\mathrm{MOE}_{\mathrm{L}}$ as the response variable and $\mathrm{V}, \mathrm{D}, \mathrm{H}$, $\mathrm{T}$, and $\mathrm{V}^{2}$ as explanatory variables were developed similarly. Multiple regression models using combinations of tree variables and, in the case of $\mathrm{MOE}_{\mathrm{L}}$, site variables, were also investigated. Further models were developed 
to describe the relationship between tree and butt log stiffness $\left(\mathrm{MOE}_{\mathrm{T}}\right.$ and $\left.\mathrm{MOE}_{\mathrm{L}}\right)$, and between breast-height diameter and the number of veneer sheets procured from each tree, $\mathrm{N}_{\mathrm{T}}$, and from each butt veneer bolt, $\mathrm{N}_{\mathrm{L}}$.

\section{Results}

\section{Mean tree stiffness for sample trees}

Mean tree stiffness $\left(\mathrm{MOE}_{\mathrm{T}}\right)$ for Site 803 is shown superimposed on the box plots of individual tree stiffness distributions in Figure 4. These values tended to decrease with decreasing standing tree acoustic velocity, particularly for the control plot A and for plot D. However, there was considerable variation about the mean. For all treatment plots, Class 1 trees, i.e. those trees with the highest velocities, had greater mean stiffness than the Class 4 trees, with the lowest velocities (Figure 4). The differences between Class 1 and 4 trees were highly significant for plots $\mathrm{A}, \mathrm{D}$, and $\mathrm{E}$ $(p<0.01)$, and significant at the 0.05 level for plots B and C.

\section{Comparison of plot means for sample trees}

By treatment, trees from plot E from Site 803 demonstrated the greatest mean stiffness $\left(\mathrm{MOE}_{\mathrm{T}}\right)$ and trees from the control plot demonstrated the lowest. The difference between plot A and E means for Site 803 were significant at the $10 \%$ level, but not at the $5 \%$ level (pvalue $=0.074)$. Mean stiffness for plots $A$ through $E$ at Site 803 was 10.2, 11.2, 10.5, 10.9, and $12.6 \mathrm{GPa}$, respectively (Table 2). Mean tree density at Site 803, with a range from 382 to $509 \mathrm{~kg} \mathrm{~m}^{-3}$, and average of $439 \mathrm{~kg} \mathrm{~m}^{-3}$, followed a similar trend. Mean tree stiffness was not determined for any plots at Site 808 .
Differences in means of the acoustic tree sample, as determined by ANOVA (Table 2), were statistically significant in comparisons of diameter at breast height and taper between the control plot and Plots B and D at both sites. However diameter growth associated with Plot E did not differ significantly from the control plot A at both sites, nor for Plot $\mathrm{C}$ at Site 803. Taper was also not significantly different between plots $\mathrm{A}$ and $\mathrm{E}$ at Site 803. Acoustic velocity was significantly lower than the control on Plots B and D at Site 808 only. For the veneer tree subsample, differences in means were not significant at the 0.05 level of significance for any of the measured tree variables.

Differences between site means were statistically significantly different in terms of velocity, height, and taper for both the acoustic tree sample and the veneer tree subsample (Table 3). Mean stiffness of the butt veneer bolt was significantly greater for Site 803 .

\section{Relationships between mean tree stiffness and tree variables}

The mean stiffness for subsample trees from Site 803 increased with increasing standing tree acoustic velocity $\left(R^{2}=0.21\right)$, while diameter at breast height and taper showed decreasing trends $\left(R^{2}=0.21\right.$ and 0.28 , respectively) as shown in Figure 5. There was no relationship between $\mathrm{MOE}_{\mathrm{T}}$ and the height of the standing tree. The scatter plots also showed some evidence of differences due to thinning treatments, with a greater proportion of trees from the un-thinned plots (A and $\mathrm{C}$ ) lying below the regression lines.

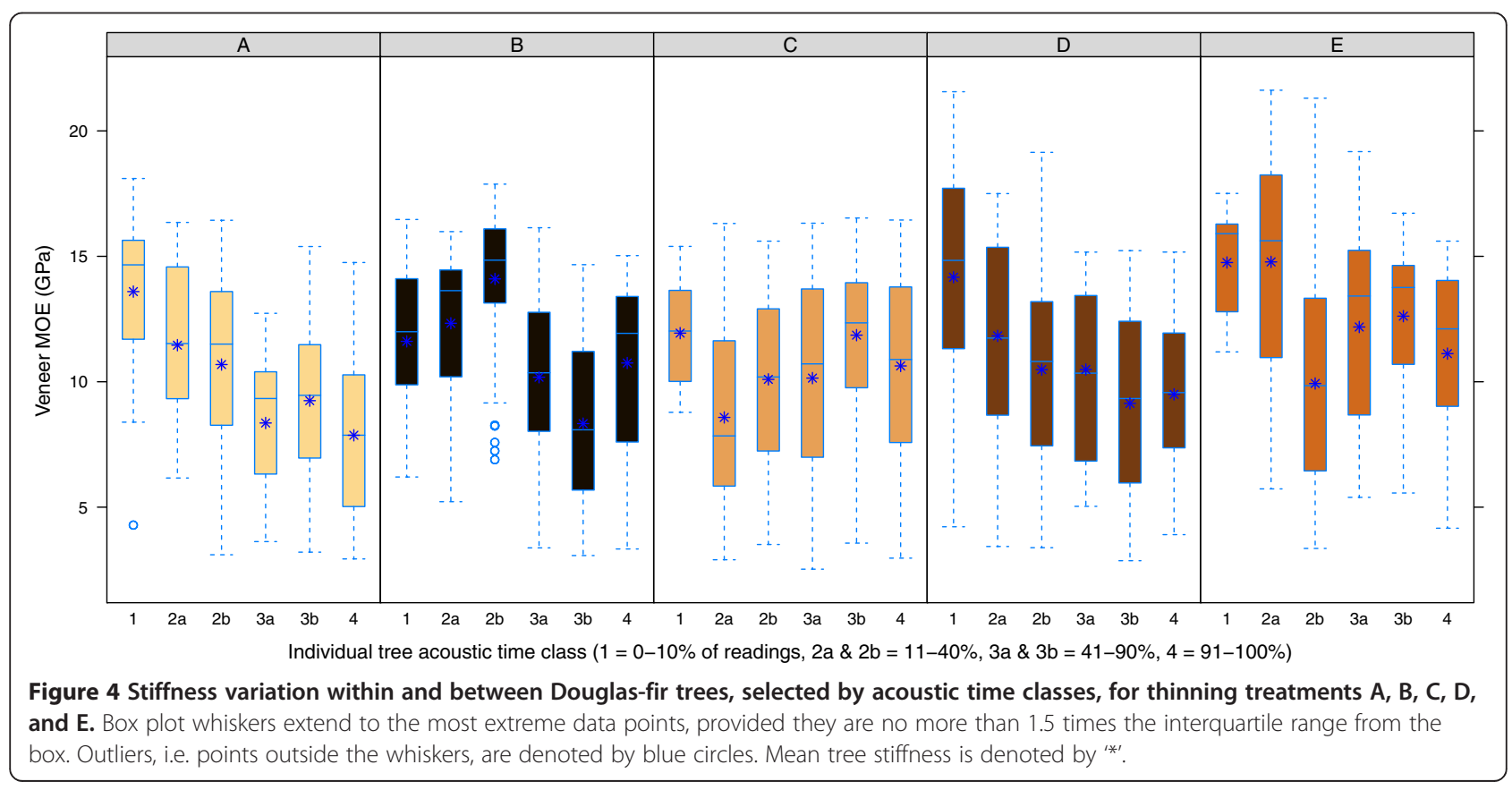


Table 2 Comparison of plot means of thinned (B, D, E) and un-thinned (A, C) plots for acoustic tree sample and veneer sub-sample trees (means with the same letter are not significantly different)

\begin{tabular}{|c|c|c|c|c|c|c|c|c|c|c|c|c|c|}
\hline \multicolumn{6}{|c|}{ Acoustic tree sample } & \multirow[b]{2}{*}{$\mathrm{N}$} & \multirow[b]{2}{*}{$\begin{array}{l}\text { Velocity } \\
\left(\mathrm{km} \mathrm{s}^{-1}\right)\end{array}$} & \multicolumn{6}{|c|}{ Veneer tree subsample } \\
\hline Plot & $\mathrm{N}$ & $\begin{array}{l}\text { Velocity } \\
\left(\mathrm{km} \mathrm{s}^{-1}\right)\end{array}$ & $\begin{array}{l}\text { Diameter } \\
\text { (cm) }\end{array}$ & $\begin{array}{l}\text { Height } \\
\text { (m) }\end{array}$ & $\begin{array}{c}\text { Taper }^{\dagger} \\
\left(\mathrm{cm} \mathrm{m}^{-1}\right)\end{array}$ & & & $\begin{array}{l}\text { Diameter } \\
(\mathrm{cm})\end{array}$ & $\begin{array}{c}\text { Height } \\
\text { (m) }\end{array}$ & $\begin{array}{c}\text { Taper }^{\dagger} \\
\left(\mathrm{cm} \mathrm{m}^{-1}\right)\end{array}$ & $\begin{array}{l}\text { Density } \\
\left(\mathrm{kg} \mathrm{m}^{-3}\right)\end{array}$ & $\mathrm{MOE}_{\mathrm{L}}$ & $\overline{\mathrm{MOE}_{\mathrm{T}}}$ \\
\hline & & & & & & & Site 803 & & & & & & \\
\hline A & 52 & 4.05ab & $36.9 b$ & $35.0 \mathrm{~b}$ & $1.05 b$ & 6 & $4.05 a$ & $34.4 a$ & $32.3 a$ & $1.06 a$ & $429 a$ & $10.9 a$ & $10.2 \mathrm{a}$ \\
\hline B & 52 & $4.00 \mathrm{~b}$ & $44.8 \mathrm{a}$ & $38.0 a$ & $1.17 a$ & 6 & $4.01 \mathrm{a}$ & $44.2 \mathrm{a}$ & $37.5 a$ & $1.17 a$ & $447 a$ & $11.3 \mathrm{a}$ & $11.2 \mathrm{a}$ \\
\hline C & 52 & $4.14 a$ & $35.1 \mathrm{~b}$ & $34.7 b$ & $1.00 \mathrm{~b}$ & 6 & $4.17 a$ & $35.6 a$ & $35.6 a$ & $1.00 \mathrm{a}$ & $423 a$ & $10.2 \mathrm{a}$ & $10.5 a$ \\
\hline $\mathrm{D}$ & 52 & $4.04 b$ & 43.3a & $36.7 \mathrm{ab}$ & $1.17 a$ & 6 & $4.04 a$ & $41.5 \mathrm{a}$ & $36.0 a$ & $1.15 \mathrm{a}$ & $445 a$ & 11.9a & 10.9a \\
\hline E & 52 & $4.01 b$ & $37.9 b$ & $35.5 b$ & $1.06 b$ & 6 & $4.01 a$ & $32.6 a$ & $32.5 a$ & $1.00 \mathrm{a}$ & $450 a$ & $12.6 \mathrm{a}$ & $12.6 a$ \\
\hline & & & & & & & Site 808 & & & & & & \\
\hline A & 52 & $3.98 a$ & $38.1 \mathrm{C}$ & 31.0a & $1.22 \mathrm{~d}$ & 4 & $3.95 a$ & $39.8 a$ & $31.9 a$ & $1.24 a$ & $426 a$ & $9.33 a$ & $\mathrm{nc}$ \\
\hline B & 52 & $3.81 \mathrm{C}$ & 43.7ab & $30.1 \mathrm{ab}$ & $1.45 b$ & 5 & $3.77 a$ & $44.1 \mathrm{a}$ & $30.8 a$ & $1.43 a$ & $428 a$ & $10.9 a$ & $\mathrm{nc}$ \\
\hline C & na & na & na & na & na & na & na & na & na & na & na & na & nc \\
\hline D & 46 & $3.86 b c$ & 46.6a & $29.7 \mathrm{~b}$ & $1.57 a$ & 6 & $3.86 a$ & $47.1 \mathrm{a}$ & $29.4 a$ & $1.60 \mathrm{a}$ & $436 a$ & 10.7a & nc \\
\hline E & 50 & $3.93 \mathrm{ab}$ & $40.8 \mathrm{bc}$ & $29.8 b$ & $1.36 c$ & 6 & $3.91 a$ & $40.9 a$ & $29.8 a$ & $1.36 a$ & $429 a$ & $10.7 a$ & nc \\
\hline
\end{tabular}

Relationships between stiffness of the butt bolt, $\mathrm{MOE}_{\mathrm{L}}$, and tree variables, are shown in Figure 6. Trends were similar to those observed for the parent tree, though the relationships were weaker.

Parameter estimates of the simple regression models for estimating mean tree stiffness and mean stiffness of the butt veneer bolt are shown in Tables 4 and 5 respectively. The strength of the relationship with $\mathrm{V}^{2}$, with allowance for an intercept term, was the same as found for $\mathrm{V}$ for both stiffness estimates (i.e. $\mathrm{MOE}_{\mathrm{T}}$ and $\mathrm{MOE}_{\mathrm{L}}$ ). When the intercept was suppressed (hence replicating Equation 1) the relationships weakened, as expected. None of the multiple regression models using combinations of tree variables was significant nor was site significant as an explanatory variable when included in regression models predicting $\mathrm{MOE}_{\mathrm{L}}$.

Although acoustic velocity was only weakly related to $\operatorname{MOE}_{T}\left(R^{2}=0.21\right)$, the upper decile of high velocity trees (i.e. Acoustic Class 1) were correctly classified as highstiffness trees but only some of the Class 4 trees were correctly classified as low stiffness (Figure 7). The smaller diameter trees (represented by the circle diameters in the figure) tended to be amongst the stiffest trees. All trees represented in the upper density quartile (i.e. with a mean density greater than $455 \mathrm{~kg} \mathrm{~m}^{-3}$ ) were stiffer than $11 \mathrm{GPa}$. In general, trees of greater density (represented in the figure by the darker circle borders) were stiffer.

\section{Relationship between tree and butt veneer bolt stiffness}

Mean stiffness of the butt veneer bolt and that of the parent tree for Site 803 were strongly correlated $\left(R^{2}=\right.$ 0.59 , Figure 8 ). The linear relationship (standard errors of the estimates shown in parentheses) was given by:

$$
M O E_{T}=\underset{(0.122)}{0.780} M O E_{L}+\underset{(1.41)}{2.22}
$$

High-stiffness trees (i.e. those with $\mathrm{MOE}_{\mathrm{T}}$ greater than 11.0 GPa) included all Class 1 trees from across the

Table 3 Comparison of site means for acoustic tree sample and veneer sub-sample trees (means with the same letter

\begin{tabular}{|c|c|c|c|c|c|c|c|c|c|c|c|c|c|}
\hline \multicolumn{6}{|c|}{ Acoustic tree sample } & \multicolumn{8}{|c|}{ Veneer tree subsample } \\
\hline Site & $\mathrm{N}$ & $\begin{array}{l}\text { Velocity } \\
\left(\mathrm{km} \mathrm{s}^{-1}\right)\end{array}$ & $\begin{array}{c}\text { Diameter } \\
\text { (cm) }\end{array}$ & $\begin{array}{l}\text { Height } \\
\text { (m) }\end{array}$ & $\begin{array}{c}\text { Taper }^{\dagger} \\
\left(\mathrm{cm} \mathrm{m}^{-1}\right)\end{array}$ & $\mathrm{N}$ & $\begin{array}{l}\text { Velocity } \\
\left(\mathrm{km} \mathrm{s}^{-1}\right)\end{array}$ & $\begin{array}{c}\text { Diameter } \\
\text { (cm) }\end{array}$ & $\begin{array}{c}\text { Height } \\
\text { (m) }\end{array}$ & $\begin{array}{c}\text { Taper }^{\dagger} \\
\left(\mathrm{cm} \mathrm{m}^{-1}\right)\end{array}$ & $\begin{array}{l}\text { Density } \\
\left(\mathrm{kg} \mathrm{m}^{-3}\right)\end{array}$ & $\begin{array}{l}\mathrm{MOE}_{\mathrm{L}} \\
(\mathrm{GPa})\end{array}$ & $\begin{array}{l}\mathrm{MOE}_{\mathrm{T}} \\
(\mathrm{GPa})\end{array}$ \\
\hline 803 & 260 & 4.05 & 39.6 & 36.0 & 1.09 & 30 & 4.06 & 37.7 & 34.8 & 1.07 & 439 & 11.4 & 11.1 \\
\hline $803^{*}$ & 208 & $4.02 \mathrm{a}$ & $40.7 a$ & $36.3 a$ & $1.11 \mathrm{~b}$ & 24 & 4.03a & $38.2 a$ & $34.6 a$ & $1.09 \mathrm{~b}$ & $443 a$ & $11.7 a$ & 11.2 \\
\hline 808 & 200 & $3.90 \mathrm{~b}$ & $42.2 \mathrm{a}$ & $30.2 b$ & $1.40 \mathrm{a}$ & 21 & $3.87 b$ & $43.2 \mathrm{a}$ & $30.3 b$ & $1.42 \mathrm{a}$ & $430 a$ & $10.5 b$ & nc \\
\hline
\end{tabular}
are not significantly different)

${ }^{\dagger}$ Calculated as the ratio of Diameter:Height.

*Comparisons conducted excluding plot $\mathrm{C}$ from Site 803 for consistency.

$\mathrm{nc}=$ not calculated. 

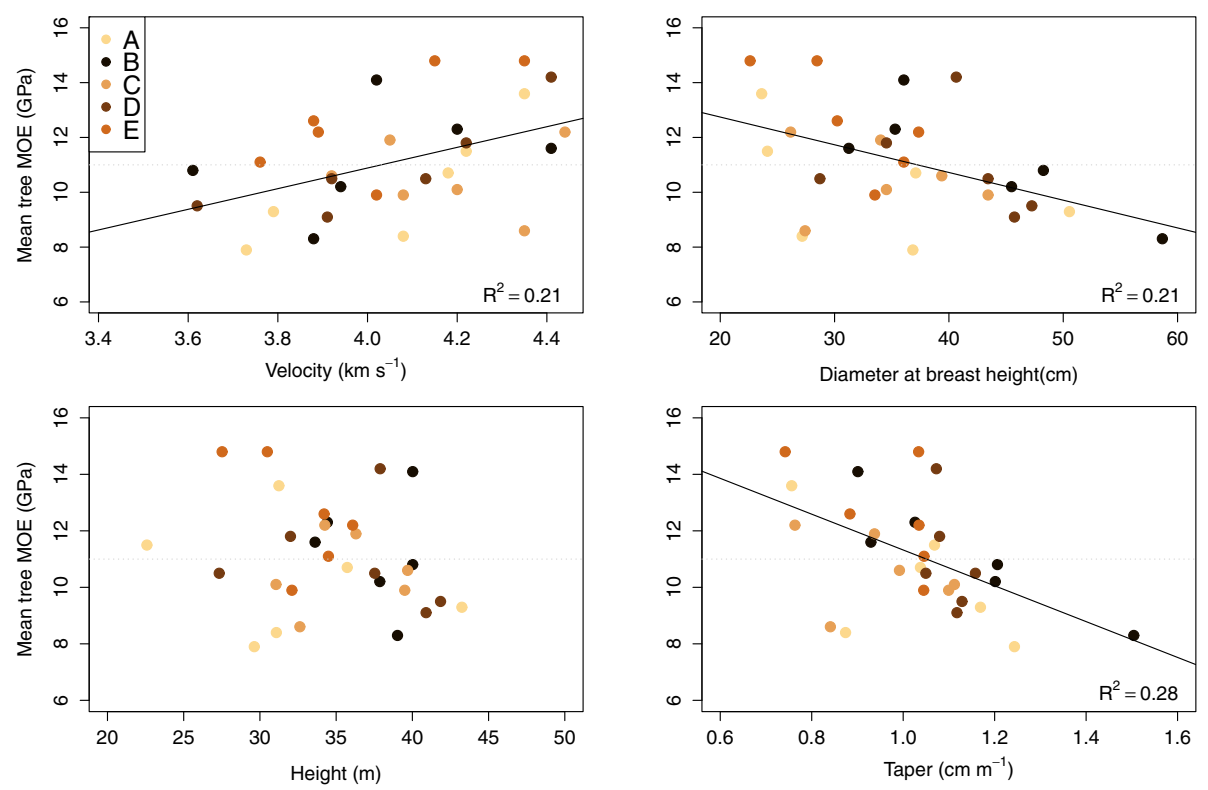

Figure 5 Relationships between mean tree stiffness and tree variables for thinning treatment A through E, at Site 803.

range of treatments and all but one (2b) tree from treatment E. All Class 4 trees, with the exception of that from treatment $\mathrm{E}$, were of low stiffness. Low-stiffness trees also included four of the six un-thinned control plot trees (A2b, A3a, A3b, and A4) at Site 803. Trees from the un-thinned Plot $\mathrm{C}$ demonstrated similar results to the control trees while trees from Plots B and D were split, approximately equally, above and below the 11.0 GPa value (Figure 8).

Relationship between tree diameter at breast height and number of peeled veneer sheets

The relationship between tree diameter at breast height and the number of veneer sheets peeled from trees at
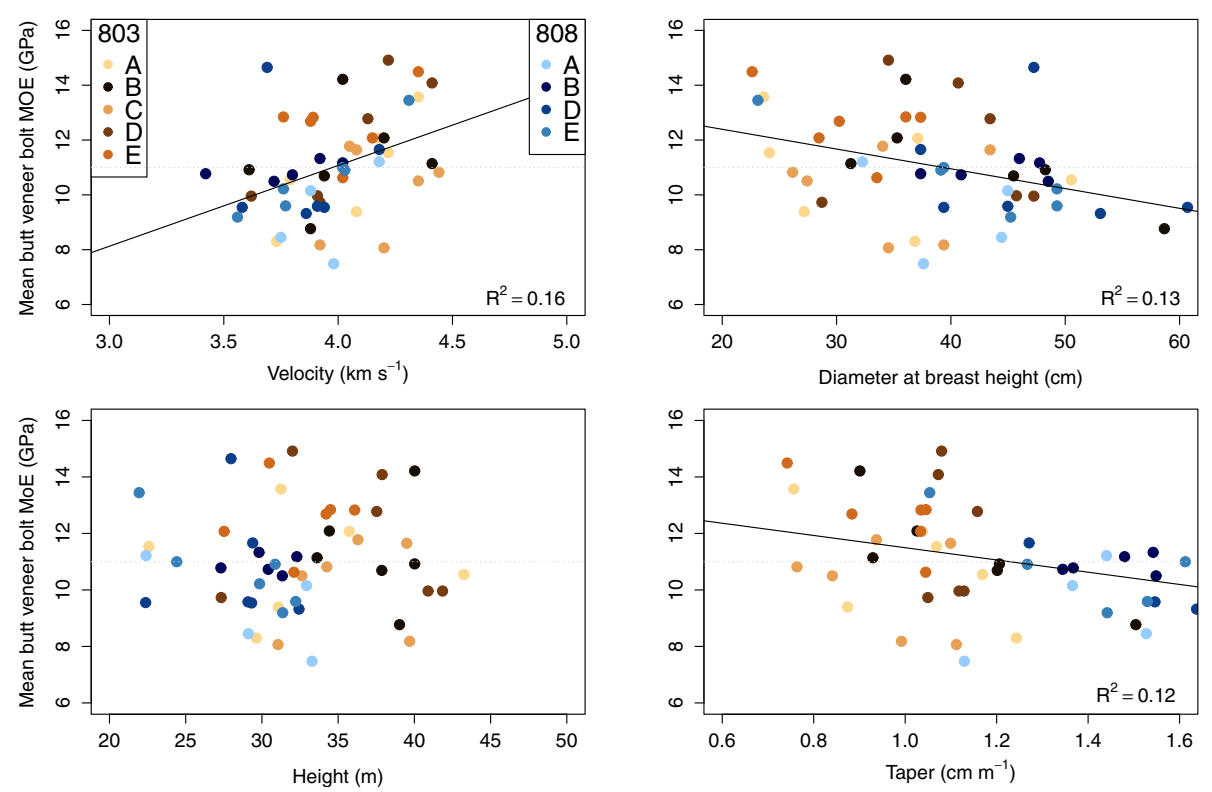

Figure 6 Relationships between butt veneer bolt stiffness and tree variables for thinning treatment A through E, at Sites 803 and 808 . 
Table 4 Fit statistics of simple regression models, $\mathrm{Y}=\mathrm{a}+\mathrm{bX}$, predicting mean tree stiffness $\left(\mathrm{MOE}_{\mathrm{T}}\right.$ ) from tree variables

\begin{tabular}{llllllll}
\hline Explanatory variable & Symbol & $\mathbf{a}$ & $\mathbf{b}$ & $\mathbf{S E}(\mathbf{a})$ & $\mathbf{S E}(\mathbf{b})$ & $\mathbf{p}$-value & $\mathbf{R}^{\mathbf{2}}$ \\
\hline Velocity & $\mathrm{V}$ & -4.18 & 3.77 & 5.58 & 1.38 & 0.011 & 0.21 \\
Diameter at breast height & $\mathrm{D}$ & 14.8 & -0.101 & 1.37 & 0.0367 & 0.010 & 0.21 \\
Taper & $\mathrm{T}$ & 17.7 & -6.34 & 2.01 & 1.92 & 0.003 & 0.28 \\
Velocity-squared & $\mathrm{V}^{2}$ & 3.38 & 0.467 & 2.82 & 0.170 & 0.010 & 0.21 \\
Velocity-squared, intercept suppressed & $\mathrm{V}^{2}$ & 0.00 & 0.670 & $\mathrm{na}$ & 0.019 & 0.020 & 0.17 \\
\hline
\end{tabular}

$\mathrm{SE}=$ standard error; $\mathrm{R}^{2}=$ coefficient of determination; $\mathrm{na}=$ not applicable.

Site $803 \mathrm{~N}_{\mathrm{T}}$ was very strong $\left(\mathrm{R}^{2}=0.90\right)$ (Figure 9, circles), as would be expected, and is given below in Equation 6.

$$
N_{T}=\begin{array}{cr}
4.76 & D-106.6 \\
(0.30) & (11.3)
\end{array}
$$

When considering both sites, a strong relationship was also found between the number of veneer sheets peeled from the butt veneer bolt and breast-height diameter (Figure 9, squares). The number of sheets peeled from the butt veneer bolt represented about 20 percent of the veneer peeled from each tree. In relation to tree diameter at breast height, the number of veneer sheets that could be expected from a $2.6 \mathrm{~m}$ butt $\log \mathrm{N}_{L}$ is given by Equation (7), $\left(R^{2}=0.73\right)$.

$$
N_{L}=\underset{(0.06)}{0.63} D-11.56
$$

However, taper was highly significant as an explanatory variable when included in the model. The augmented equation, with an $\mathrm{R}^{2}$ of 0.77 , is given below.

$$
N_{L}=\underset{(0.08)}{0.80} D-\underset{(2.04)}{6.37} T-10.06
$$

\section{Discussion}

This study did not find a significant reduction in stiffness due to thinning in contrast to past research. Mean stiffness of trees from thinned plots was not lower than those from un-thinned plots. However, the sample size was small at the tree level, with only six trees per plot. Differences in stiffness would need to be considerably larger to be judged as significantly different as determined by ANOVA. Alternatively, the sample size would need to be considerably larger. A larger trial is unlikely to occur in the short term given that the current study processed thousands of veneer sheets. However, further investigation of the thinning regime on Plot $\mathrm{E}$ may be worthwhile, given the practical importance of the observed increase in mean stiffness even though this was not statistically significant.

Mean tree stiffness was derived from stiffness measurements of all possible veneer sheets that could be peeled from each tree, and then aggregated at the tree level. No attempt was made to "correct" for the fact that veneer sheets were both processed and dried, and that measurements were made on standing trees, as the objective was to establish relationships between the two in order to improve decision-support tools for assisting landowners and managers in making improved marketing decisions.

However, relationships between mean tree stiffness and tree variables were either weakly (acoustic velocity, $\mathrm{V}$, diameter at breast height, D) or moderately (taper, $\mathrm{T}$ ) correlated. The weak correlation between mean tree stiffness and acoustic velocity found here for Douglas-fir is the same as that found by Blakemore et al. (2010) in their study of maritime pine (Pinus pinaster Aiton) $\left(\mathrm{R}^{2}=0.21\right)$ in which mean tree stiffness was based on

\begin{tabular}{|c|c|c|c|c|c|c|c|}
\hline Explanatory variable & Symbol & a & b & $\mathrm{SE}(\mathrm{a})$ & $\mathrm{SE}(\mathrm{b})$ & p-value & $\mathrm{R}^{2}$ \\
\hline Velocity & V & -0.704 & 2.94 & 3.85 & 0.97 & 0.004 & 0.16 \\
\hline Diameter at breast height & $\mathrm{D}$ & 13.8 & -0.072 & 1.07 & 0.027 & 0.009 & 0.13 \\
\hline Taper & $\mathrm{T}$ & 13.7 & -2.17 & 1.03 & 0.82 & 0.011 & 0.12 \\
\hline Velocity-squared & $V^{2}$ & 5.06 & 0.375 & 1.94 & 0.121 & 0.003 & 0.16 \\
\hline Velocity-squared, intercept suppressed & $V^{2}$ & 0.00 & 0.688 & na & 0.015 & 0.121 & 0.05 \\
\hline
\end{tabular}
average board stiffness. In that study, a considerably greater association was found with radiata pine $\left(R^{2}=0.62\right)$. Estimated stiffness following the wave equation (i.e. $\mathrm{V}^{2}$ )

Table 5 Fit statistics of simple regression models, $\mathrm{Y}=\mathbf{a}+\mathbf{b X}$, predicting mean stiffness of the butt veneer bolt (MOE $\mathrm{L}_{\mathrm{L}}$ ) from tree variables

$\mathrm{SE}=$ standard error; $\mathrm{R}^{2}=$ coefficient of determination; $\mathrm{na}=$ not applicable. 


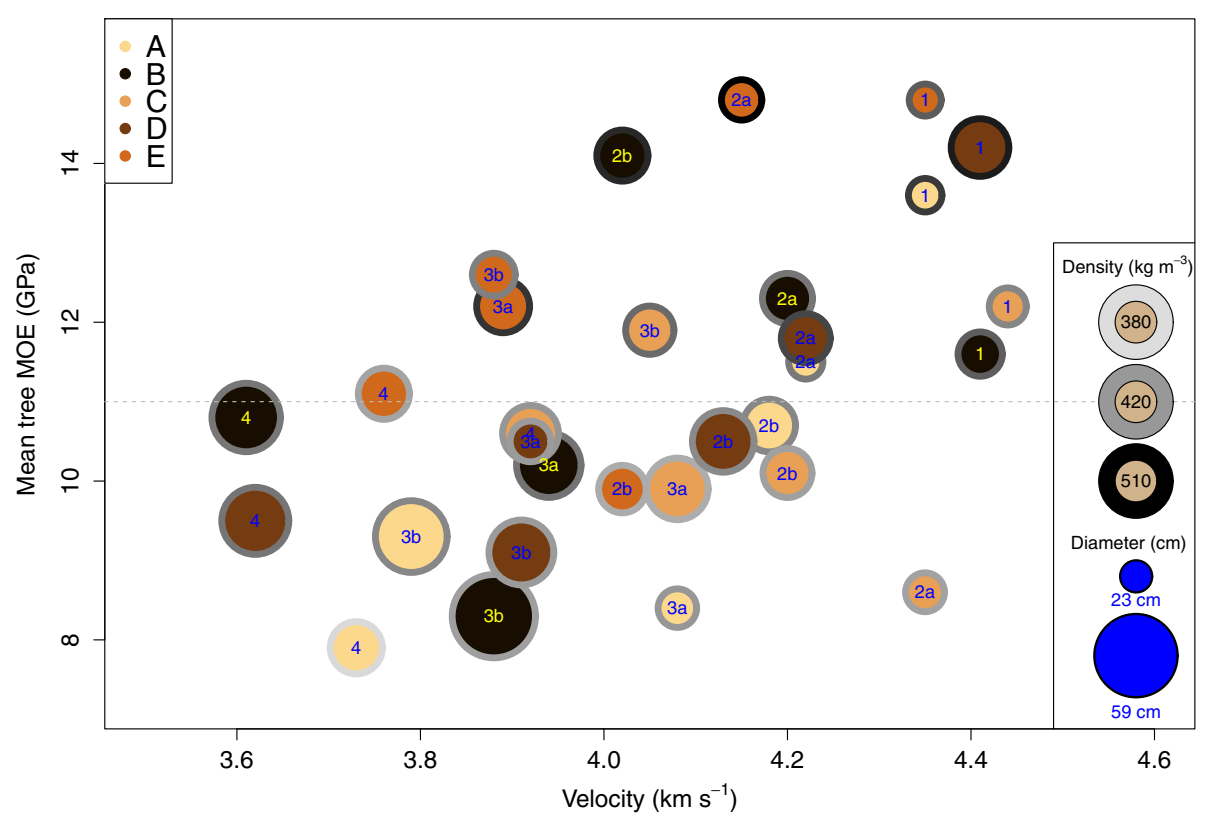

Figure 7 Summary of relationships between mean tree stiffness and tree variables. The diameter of the circle represents tree diameter at breast height, the circle background colour represents the thinning treatment, and the border colour represents mean density calculated from all veneer procured from each tree.

was no better a predictor than V. Furthermore, there is no evidence of a quadratic trend in Figure 5 (top left). As the trees were sampled through stratification of acoustic readings, the authors are confident that the range in acoustic velocity is satisfactorily represented for the trees in this study, which were about 50 years old.
The relative lack of fit between mean tree stiffness and that derived from the wave equation with $\mathrm{V}^{2}$ as a predictor variable may be due to a number of factors. Firstly, there is the assumption of constant density. It should be noted that it is not the magnitude of the constant that is in question, rather the use of that constant

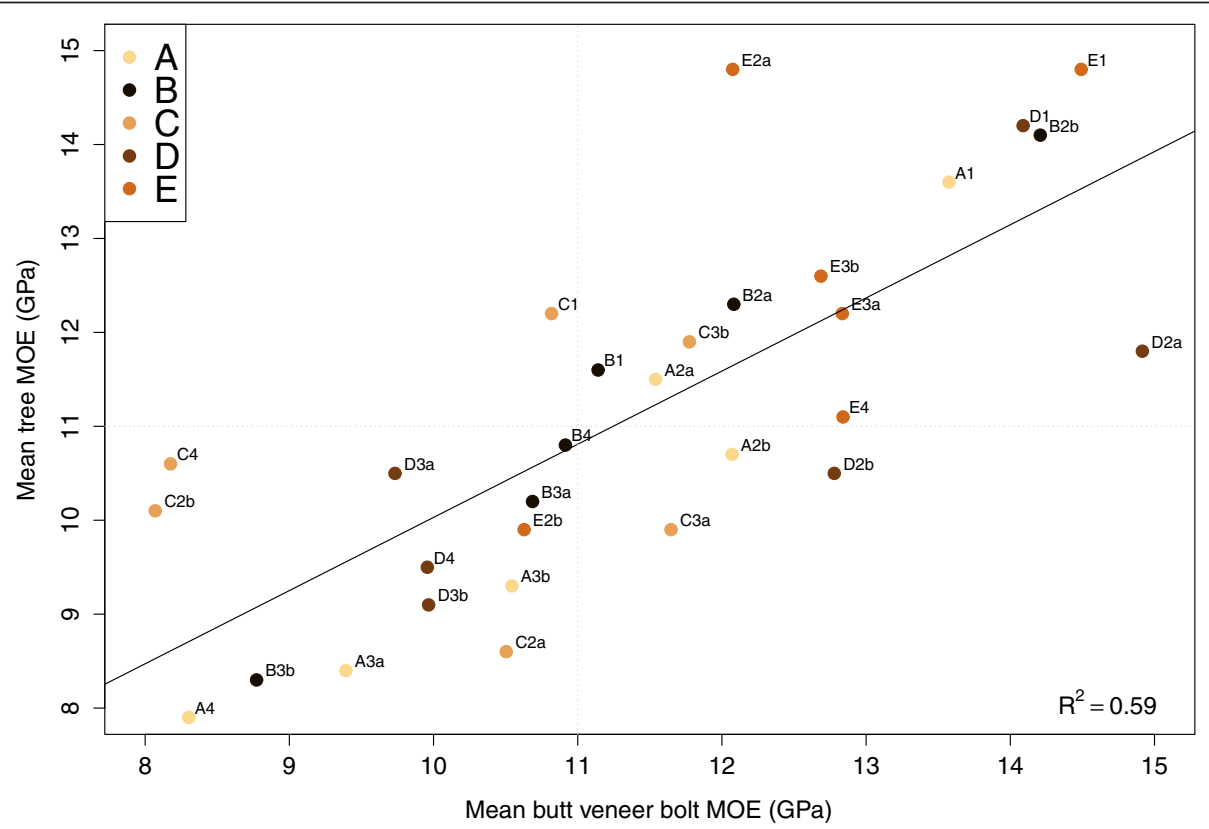

Figure 8 Relationship between mean tree stiffness and butt veneer bolt stiffness for subsampled trees from Site 803 . 


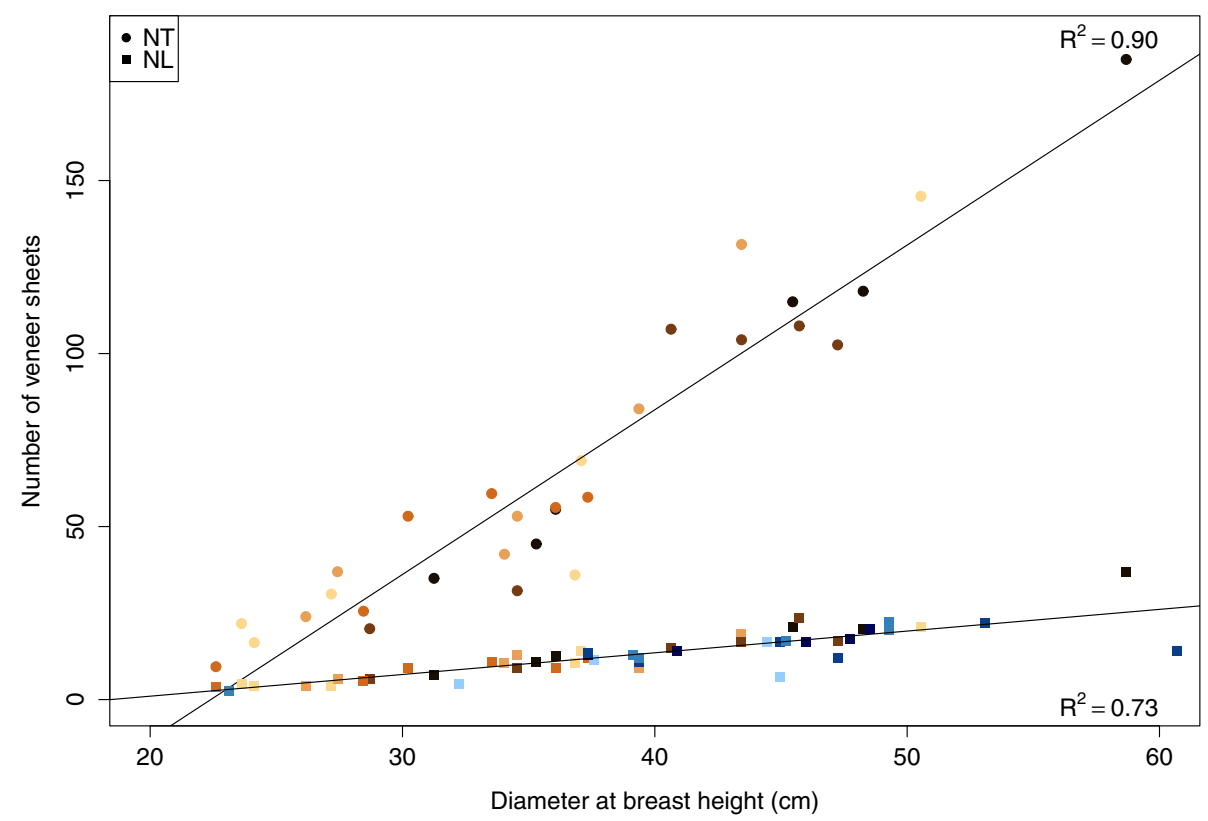

Figure 9 Relationship between tree diameter and the number of veneer sheets peeled from the tree (NT) and from the butt veneer bolt (NL) at Sites $\mathbf{8 0 3}$ (brown shaded circles) and $\mathbf{8 0 8}$ (blue shaded circles). Darker colours represent increased thinning intensity (refer Figure 1).

across all trees and treatments. The magnitude of the constant has no effect on the strength of the association, or on the significance levels, as it simply rescales the predictor data (in this case $\mathrm{V}^{2}$ ). This is a feature of all linear regression models. Secondly, acoustic time-offlight tools measure the transit time of an acoustic wave as it travels through outerwood. This suggests that outerwood density may provide improved stem stiffness results. However, Raymond et al. (2008) found outerwood density to be a poor predictor of mean stem stiffness in radiata pine.

It is possible that other factors may have contributed to the results presented here. For example, the climate regime in the Pacific Northwest is characterised by a summer drought (Waring and Franklin 1979) that causes severe summer water stress and soil moisture deficits that result in induced dormancy during the time when dense, stiff latewood would be produced. By reducing competition among trees for water, thinning can delay or reduce these effects so residual trees produce more dense, stiff latewood as observed in this analysis of veneer. The effects of drought and thinning on increasing and redistributing growth along the stem were documented for the study sites by Kantavichai (2011). Thinning also increases exposure to wind stress and other studies (reviewed by Telewski 1995) have found that this also produces a redistribution of growth along the bole and a tendency to produce stiffer wood, which in the extreme is compression wood. Branches can also have an effect on tree acoustic velocity measurements (Lasserre et al. 2007) with Amishev and Murphy (2008) finding a negative correlation between acoustic velocity and presence and size of branches. Whether these variables have influenced the results obtained here remains an open question.

The trees on the thinned plots, Plots B, D, and E, were thinned at 31-33 years of age. This is relatively late in terms of thinning practices. Thinning performed at a young stand age (less than 20 years), will have a greater impact on stiffness as the trees are still in the juvenile wood production stage. The juvenile wood core was most likely fairly well established as 20 years of age is often used as the transition from juvenile wood to mature wood for Douglas-fir (Fahey et al. 1991; DiLucca 1989).

Though thinned at a late age, thinning treatments $B$ and $\mathrm{D}$ were effective in increasing diameter growth (Table 2) at both sites. This result is consistent with that found by Reukema (1975), Tappeiner et al. (1982), and others. Diameter growth of treatment E however, was relatively unchanged in comparison to the control plot. Thinning, even at this late age, appears to have had adversely affected tree form with greater taper exhibited on the thinned plots, particularly plots B and D (Table 2), consistent with the findings of Weiskittel et al. (2006). Taper also adversely affected tree stiffness (Figure 5 and Table 4), consistent with that noted by Lindström et al. (2009), in assessing the stiffness of Scots pine (Pinus sylvestris L.) trees.

Although there is evidence of a trade-off between managing plots for high quality, high-stiffness products 
and for high volume production, the regime applied to Plot E represents somewhat of a compromise between the two. Of the thinned plots, plot $\mathrm{E}$ had the fewest trees removed during thinning (Figure 1), and, at harvest, had a mean diameter similar to that of the un-thinned plots, yet also produced trees of high stiffness.

In general, the stiffest veneer trees were the smallest diameter. This quality versus quantity issue was noted by Jayawickrama et al. (2009) in terms of the likely cost of tree improvement programmes (i.e. loss in volume to gain additional stiffness). If breeding programmes are successful in breeding high-stiffness stock, then a silvicultural treatment that does not severely reduce veneer production but maintains a relatively high level of stiffness may be a valid option. However, if breeding programmes do not select for stiffness then there is a risk to future product stiffness because "failing to score stiffness could result in low-stiffness selections becoming significant components of breeding or production populations" (Jayawickrama et al. 2009).

While no economic analyses were conducted on these data, better quality material often translates to higher value, but if that value is not great enough to offset the decrease in volume, then land management decisions will be made accordingly. These decisions will need to be made at a young stand age when pricing structure at time of harvest is unknown.

\section{Conclusions}

Mean tree stiffness was found to be positively correlated to acoustic velocity and negatively correlated to both diameter and taper. Acoustic velocity testing successfully identified the uppermost decile of trees with the highest MOE and thus, could be used to select trees with potential to render high-value products requiring high stiffness.

In general, high-stiffness trees had higher density and smaller diameters with taper less than $1.2 \mathrm{~cm} \mathrm{~m}^{-1}$. However, trees with smaller diameters produce less veneer. As a general rule of thumb, the number of sheets in the butt veneer bolt can be estimated from $80 \%$ of the diameter, less 6.5 sheets for each unit of taper, and the number of veneer sheets in the tree derived by multiplying that number by 5 . Thus there is a trade-off between forestry practices that target high value (stiffness) production and those that target high volume production.

Stiffness estimated with $\mathrm{V}^{2}$, representing the wave equation under the assumption of constant wood density, was only weakly correlated to mean tree stiffness. Thus, pre-harvest veneer stiffness evaluation of Douglasfir stands using acoustic velocity alone is currently not reliable as was also concluded by Amishev and Murphy (2008). To more accurately monitor stiffness in Douglasfir trees and to enable improved decision making, it may be necessary to derive estimates of wood density (using in situ approaches such as described by Isik and $\mathrm{Li}$ (2003) and El-Kassaby et al. (2011) or routine outerwood density cores) across a matrix of sites, treatments, and ages.

The authors recommend that the assumption of constant density, often applied in research exercises that utilise acoustic tools, be tested more rigorously, particularly if the tool and the assumption of constant density are to be applied to assess stiffness across stands of differing ages and differing silvicultural treatments.

\section{Competing interests}

The authors declare that they have no competing interests.

\section{Authors' contributions}

All authors contributed towards the writing of the paper. EL organised and participated in field data collection, and participated in the draft of the manuscript. CT analysed the data, evaluated the results, created the figures, and was also involved in drafting the manuscript. DD was active in project management, participated in collection of field data and was responsible for data preparation. DB was involved in writing the grant proposal, experimental design, and project management. All authors read and approved the final manuscript.

\section{Authors' information}

EL, a research forest products technologist at the USDA FS with a background in forest products (MS Forest Products), is leader of the Wood Quality Project that sits within the US Stand Management Cooperative. CT, a senior scientist at Scion with a background in mathematical modelling (PhD Engineering Science), is principal investigator on the USDA-Scion Joint Venture Agreement. DD, formerly of the USDA FS, has a background in operations research and forest engineering (PhD Industrial Engineering), special competence in sustainable forest management, and is proprietor of Blue Ox Forestry. DB, an emeritus professor at the University of Washington (PhD Forestry), has special interest in developing systems that connect silvicultural methods, genetic improvement, wood quality, and product value.

\section{Acknowledgements}

The authors thank the contributions of member partners of the Stand Management and Precision Forestry Cooperatives, the Rural Technology Initiative Program at the University of Washington's School of Environmental and Forest Sciences, the USFS Pacific Northwest Research Station, and $\mathrm{CHH}$ FibreGen. We also acknowledge statistical advice provided by Mark Kimberley of Scion and suggestions from anonymous reviewers. This research effort was supported by the Sustainable Forest Productivity component of Agenda 2020, a joint effort of the USDA Forest Service Research \& Development and the American Forest and Paper Association. Funds were provided by the USFS Rocky Mountain Research Station, the University of Washington, School of Environmental and Forest Sciences, the USFS Pacific Northwest Research Station, and the USFS Forest Products Laboratory. In addition, research cumulating in this publication was supported by a Joint Venture Agreement between the New Zealand Forest Research Institute Limited, trading as Scion, and the USDA Forest Service, and through Future Forests Research Limited, a research partnership between Scion and New Zealand forest industries.

\section{Author details}

${ }^{1}$ US Forest Service, Portland Forestry Sciences Laboratory, 620 SW Main, Suite 400, Portland, OR 97205, USA. ${ }^{2}$ New Zealand Forest Research Institute Ltd (Scion), 49 Sala Street, Rotorua 3010, Private Bag 3020, Rotorua 3046, New Zealand. ${ }^{3}$ Blue Ox Forestry, Paso Robles, CA 93446, USA. ${ }^{4}$ School of Environmental and Forest Sciences, University of Washington, 4581 University Way NE, Seattle, WA 98101, USA.

Received: 27 March 2013 Accepted: 11 December 2013 Published: 09 Jan 2014

\section{References}

Amishev, D, \& Murphy, GE. (2008). Preharvest veneer quality evaluation of Douglas-fir stands using time-of-flight acoustic technique. Wood and Fiber Science, 40(4), 587-598. 
Auty, D, \& Achim, A. (2008). The relationship between standing tree acoustic assessment and timber quality in Scots pine and the practical implications for assessing timber quality from naturally regenerated stands. Forestry, 81, 475-487.

Bender, BJ, Mann, M, Backofen, R, \& Spiecker, H. (2012). Microstructure alignment of wood density profiles: An approach to equalize radial differences in growth rate. Trees - Structure and Function, 26(4), 1267-1274.

Blakemore, P, Cown, DJ, Dumbrell, I, McKinley, RB, Lyon, A, Barr, B, \& Northway, R. (2010). Western Australian Softwood Resource Evaluation: a survey of key characteristics of the Pinus radiata and Pinus pinaster resources in Western Australia with links to product performance of trees sampled from each resource, as determined by a processing. Australia: Forest and Wood Products. Project No: PNC059-0809. Available at: http://www.fwpa.com.au/WesternAustralian-Softwood-Resource-Evaluation (accessed Dec. 19, 2013).

Briggs, D, Thienel, G, Turnblom, E, Lowell, E, Dykstra, D, Ross, RJ, Wang, X, \& Carter, P. (2008). Influence of thinning on acoustic velocity of Douglas-fir trees in western Washington and western Oregon. In Proceedings of the 15th International Symposium on Nondestructive Testing of Wood (pp. 113-123). Duluth, Minnesota, USA: Western Forestry and Conservation Association Wood Quality Workshop.

Cave, ID, \& Walker, JCF. (1994). Stiffness of wood in fast-grown plantation softwoods and the influence of microfibril angle. Forest Products Journal, 44(5), 43-48.

Chauhan, SS, \& Walker, JFC. (2006). Variations in acoustic velocity and density with age, and their interrelationships in radiata pine. Forest Ecology and Management, 229, 388-394.

Curtis, RO. (1982). A simple index of stand density for Douglas-fir. Forest Science, 28, 92-94.

Curtis, RO, \& Reukema, DL. (1970). Crown development and site estimates in a Douglas-fir plantation spacing test. Forest Science, 16, 287-301.

DiLucca, CM. (1989). Juvenile-mature wood transition. In RM Kellogg (Ed.), Second growth Douglas-fir: its management and conversion for value. Publication No. SP-32 (pp. 23-38). Vancouver, BC, Canada: Forintek Canada Corp.

El-Kassaby, YA, Mansfield, S, Isik, F, \& Stoehr, M. (2011). In situ wood quality assessment in Douglas-fir. Tree Genetics and Genomes, 7(3), 553-561.

Fahey, TD, Cahill, JM, Snellgrove, TA, \& Heath, LS. (1991). Lumber and veneer recovery from intensively managed young-growth Douglas-fir. Research Paper PNW-RP-437. Portland, OR, USA: USDA Forest Service Pacific Northwest Research Station.

Gartner, BL, North, EM, Johnson, GR, \& Singleton, R. (2002). Effects of live crown on vertical patterns of wood density and growth in Douglas-fir. Canadian Journal Forest Research, 32(3), 439-447.

Huang, CL. (2000). Predicting lumber stiffness of standing trees. In Proceedings of the 12th International Symposium on Nondestructive Testing of Wood (pp. 173-179). Sopron, Hungary: University of Western Hungary.

Isik, F, \& Li, B. (2003). Rapid assessment of wood density of live trees using the Resistograph for selection in tree improvement programs. Canadian Journal of Forest Research, 33, 2426-2435.

Jayawickrama, KJS, Ye, TZ, Gupta, R, \& Cherry, ML. (2009). Including wood stiffness in tree improvement of coastal Douglas-fir in the US Pacific Northwest: A literature review and synthesis. Research Contribution 50. Corvallis, OR, USA: Forest Research Laboratory, Oregon State University.

Johnson, GR, \& Gartner, BL. (2006). Genetic variation in basic density and modulus of elasticity of coastal Douglas fir. Tree Genetics \& Genomes, 3, 25-33.

Jozsa, LA, Richards, J, \& Johnson, SG. (1989). Relative density. In RM Kellogg (Ed.), Second Growth Douglas-Fir: Its Management and Conversion for Value. Special Publication No. SP-32 (pp. 5-22). Vancouver, BC, Canada: Forintek Canada Corporation.

Kang, H-Y, Kang, C-W, \& Matsumura, J. (2011). Application of ultrasonic technology for predicting the final MC of kiln-dried softwoods. Journal of the Faculty of Agriculture, Kyushu University, 56(2), 307-312.

Kantavichai, R. (2011). Effects of climate and thinning on Coastal Douglas-fir annual biomass growth at four sites. PhD Dissertation: School of Forest Resources, University of Washington, Seattle, WA.

Kennedy, RW. (1995). Coniferous wood quality in the future: concerns and strategies. Wood Science and Technology, 29, 321-338.

Kennedy, RW, \& Warren, WG. (1969). Within-tree variation in physical and chemical properties of Douglas-fir. FO-FTB-69-4/4. In Proceedings of Food and Agriculture Organization Second World Consultation on Forest Tree Breeding, August 7-16, 1969 (Vol 1, pp. 393-417). Rome, Italy: Food and Agriculture Organization of the United Nations.
King, JE. (1966). Site index curves for Douglas-fir in the Pacific Northwest. Weyerhaeuser Forestry Paper No. 8. Centralia, WA, USA: Forest Research Center.

Langum, CE, Yadama, V, \& Lowell, EC. (2009). Physical and mechanical properties of young-growth Douglas-fir and western hemlock from western Washington. Forest Products Journal, 59(11/12), 37-47.

Lasserre, JP, Mason, E, \& Watt, M. (2004). The influence of initial stocking on corewood stiffness in a clonal experiment on 11-year-old Pinus radiata D. Don. New Zealand Journal of Forestry, 49(2), 18-23.

Lasserre, JP, Mason, EG, \& Watt, MS. (2007). Assessing corewood acoustic velocity and modulus of elasticity with two impact based instruments in 11-year-old trees from a clonal spacing experiment of Pinus radiata D. Don. Forest Ecology and Management, 239, 217-221. doi:10.1016/j.foreco.2006.12.009.

Lindström, H, Harris, P, \& Nakada, K. (2002). Methods for measuring stiffness of young trees. Holz als Roh- und Werkstoff, 60, 165-174.

Lindström, H, Reale, M, \& Grekin, M. (2009). Using non-destructive testing to assess modulus of elasticity of Pinus sylvestris trees. Scandanavian Journal of Forest Research, 24, 247-257.

McArdle, RE, Meyer, WH, \& Bruce, D. (1961). The yield of Douglas-fir in the Pacific Northwest. Technical Bulletin 201 (Revised). Washington, DC, USA: United States Department of Agriculture.

Maguire, DA, Bennett, WS, Kershaw, JA, Jr, Gonyea, R, \& Chappell, HN. (1991). Establishment Report. Stand Management Cooperative Silviculture project field installations. Contribution No. 72. Seattle, WA, USA: Stand Management Cooperative, College of Forest Resources, University of Washington, Institute of Forest Resources.

Megraw, RA. (1986). Douglas-fir wood properties. In CD Oliver, DP Hanley, \& JA Johnson (Eds.), Douglas-Fir: Stand Management for the Future (pp. 81-96). Contribution No. 55. Seattle, WA, USA: College of Forest Resources, Institute of Forest Resources, University of Washington.

Moore, JR, Lyon, AJ, Searles, GJ, \& Vihermaa, LE. (2009). The effects of site and stand factors on the tree and wood quality of Sitka Spruce growing in the United Kingdom. Silva Fennica, 43, 383-396.

Mora, CR, Schimleck, LR, Isik, F, Mahon, JM, Clark, A, III, \& Daniels, RF. (2009). Relationship between acoustic varaibles and different measures of stiffness in standing Pinus taeda trees. Canadian Jourrnal of Forest Research, 39, $1421-1429$.

Pellerin, RF, \& Ross, RJ. (2002). Non-destructive evaluation of Wood. Madison, WI, USA: Forest Products Society.

Quinn, G, \& Keough, M. (2002). Experimental Design and Data Analysis for Biologists. Chap. 8. Cambridge, UK: Cambridge University Press.

R Development Core Team. (2013). R: A language and environment for statistical computing. Vienna, Austria: R Foundation for Statistical Computing

Raymond, CA, Joe, B, Anderson, DW, \& Watt, DJ. (2008). Effect of thinning on relationships between three measures of wood stiffness in Pinus radiata: standing trees vs. logs vs. short clear specimens. Canadian Journal of Forest Research, 48, 2870-2879.

Reukema, DL. (1975). Guidelines for precommercial thinning of Douglas-fir. General Technical Report PNW 30. Portland, OR, USA: USDA Forest Service, Pacific Northwest Forest and Range Experiment Station.

Sanio, K. (1872). On the size of the wood cells of the Scotch pine (Pinus silvestris). Jahrbücher für Wissenschaftliche Botanik, 8, 401-420.

Shelbourne, CJA, Harris, JM, Tustin, JR, \& Whiteside, ID. (1973). The relationship of timber stiffness to branch and stem morphology and wood properties in plantation-grown Douglas fir in New Zealand. Genetics and Tree Improvement Report 59. Rotorua, New Zealand: Forest Research Institute.

Shelbourne, CJA, Low, CB, Gea, LD, \& Knowles, RL. (2007). Achievements in forest tree genetic improvement in Australia and New Zealand 5: Genetic improvement of Douglas-fir in New Zealand. Australian Forestry, 70, 28-32.

Tappeiner, JC, Bell, JF, \& Brodie, JD. (1982). Response of young Douglas-fir to 16 years of intensive thinning. Research Bulletin 38. Corvallis, OR, USA: Forest Research Laboratory, Oregon State University.

Telewski, FW. (1995). Wind induced physiological and developmental responses in trees. In MP Coutts \& J Grace (Eds.), Wind and trees (pp. 237-263). Cambridge, UK: Cambridge University Press.

Todoroki, CL, Lowell, EC, Dykstra, DP, \& Briggs, DG. (2012). Maps and models of density and stiffness within individual Douglas-fir trees. New Zealand Journal of Forestry Science, 42, 1-13.

Trendelenburg, R. (1936). Variations in the density of important coniferous timbers, due to locality, habitat and differences in individual trees. Oxford, UK: Imperial Forestry Institute, University of Oxford. 
Vikram, V, Cherry, ML, Briggs, D, Cress, DW, Evans, R, \& Howe, GT. (2011). Stiffness of Douglas-fir lumber: effects of wood properties and genetics. Canadian Journal of Forest Research, 41, 1160-1173.

Waddell, DR, Weyermann, DL, \& Lambert, MB. (1987). Estimating the weight of Douglas-fir tree boles and logs with an iterative computer model. Research Paper PNW-RP-374. Portland, OR, USA: USDA Forest Service, Pacific Northwest Research Station.

Wang, X. (2013). Acoustic measurements on trees and logs: a review and analysis. Wood Science \& Technology, 47(5), 965-975.

Wang, X, Ross, RJ, McClellan, M, Barbour, RJ, Erickson, JR, Forsman, JW, \& McGinnis, GD. (2001). Nondestructive evaluation of standing trees with a stress wave method. Wood and Fiber Science, 33, 522-533.

Wang, SY, Lin, FC, Jane, MC, Lin, CJ, \& Hung, CP. (2000). Effects of thinning and pruning on DBH and ultrasonic wave velocity in Taiwania cryptomerioide. Whistler Resort, BC, Canada: World Conference on Timber Engineering.

Waring, RH, \& Franklin, JF. (1979). Evergreen coniferous forests of the Pacific Northwest. Science, 204(4400), 1380-1386.

Weiskittel, AR, Maguire, DA, Monserud, RA, Rose, R, \& Turnblom, EC. (2006). Intensive management influence on Douglas fir stem form, branch characteristics, and simulated product recovery. New Zealand Journal of Forestry Science, 36, 293-312.

Wellwood, RW, \& Smith, JHG. (1962). Variation in some important qualities of wood from young Douglas-fir and hemlock trees. Research Paper No. 50. Vancouver, BC, Canada: Faculty of Forestry, University of British Columbia.

Wessels, CB, Malan, FS, \& Rypstra, T. (2011). A review of measurement methods used on standing trees for the prediction of some mechanical properties of timber. European Journal of Forest Research, 130, 881-893.

Wielinga, B, Raymond, CA, James, R, \& Matheson, AC. (2009). Effect of green density values on Pinus radiata stiffness estimation using a stress-wave technique. New Zealand Journal of Forestry Science, 39, 71-79.

Zobel, BJ, \& van Buijtenen, JP. (1989). Wood variation its causes and control. Springer series in wood science. New York, USA: Springer-Verlag New York Inc.

\subsection{6/1179-5395-44-1}

Cite this article as: Lowell et al: Linking acoustic velocity of standing Douglas-fir trees to veneer stiffness: a tree-log-product study across thinning treatments. New Zealand Journal of Forestry Science 2014, 44:1

\section{Submit your manuscript to a SpringerOpen ${ }^{\odot}$ journal and benefit from:}

- Convenient online submission

- Rigorous peer review

- Immediate publication on acceptance

- Open access: articles freely available online

- High visibility within the field

- Retaining the copyright to your article

Submit your next manuscript at $\gg$ springeropen.com 